\title{
Eclampsia-scenario in a hospital- a ten years study
}

\author{
Pal A ${ }^{1}$, Bhattacharyya $\mathrm{R}^{1}$, Adhikari $\mathrm{S}^{1}$, Roy $\mathrm{A}^{1}$, Chakrabarty $\mathrm{D}^{2}$, Ghosh $\mathrm{P}^{2}$, Banerjee $\mathrm{C}^{3}$ \\ ${ }^{1}$ Department of Gynaecology \& Obstetrics, Burdwan Medical College, Burdwan, ${ }^{2}$ Department of \\ Community Medicine, Medical College, Kolkata, ${ }^{3}$ WBHS.
}

\begin{abstract}
This cross sectional record based institutional study was conducted in the Department of Obstetrics \& Gynaecology, Burdwan Medical College, Burdwan over ten years (1999-2008) aiming analysis of eclamptic mothers for evaluation of maternal and perinatal outcome with different anticonvulsant medications. Total 5991 pregnant mothers with eclampsia admitted in the inpatient department of the tertiary care teaching hospital were recruited for the study, irrespective of their previous antenatal check up history. Subjects with known seizure disorders were excluded from the study. The subjects were managed according to standard regimens (Menon, Ph-sodium, diazepam \& magnesium sulphate) and results were documented in standardised format. Case fatality rate, mean induction delivery time $\&$ birth-weight, perinatal mortality rates were recorded. Study reveals that the incidence of eclampsia $<20$ years was $6.97 \%$ and majority $(5.41 \%)$ came from rural areas. Eclampsia was noted primarily in primigravida $(7.43 \%)$ and unbooked $(6.41 \%)$ mothers. Ante partum eclampsia predominated $(64 \%)$ and incidence of caesarean section was $22.25 \%$. The overall case fatality rate was $6.05 \%$ and eclampsia contributed $27.85 \%$ of all maternal deaths during the last two years of the study period. The overall incidence of low birth weight baby was $26.96 \%$ and perinatal mortality was $30.33 \%(1411 / 4651)$. The incidence of perinatal mortality and low birth weight babies are lower in the last 4 years when compared to earlier studies. Proper socio-demographic assessment of pregnancy with eclampsia, planned delivery, shorter induction delivery interval, good control of convulsion by magnesium sulphate, intensive intranatal monitoring causes less maternal and perinatal morbidity and mortality.
\end{abstract}

\section{Introduction}

Eclampsia is a multi-system disorder with complex pathogenesis. Majority of the death occurs in the developing countries and most of them are preventable. Eclampsia causes $12 \%$ of all global maternal deaths ${ }^{1}$. The eclamptic convulsion is a major source of perinatal morbidity or mortality unless expertly managed ${ }^{2}$. In India maternal mortality rate in eclampsia is very high. The figure ranges from $8-14 \%^{3-5}$ and perinatal mortality varies from $24-34 \%$. The role of injection magnesium sulphate as an anticonvulsant is better over diazepam and phenytoin sodium ${ }^{8}$.

The study was carried out to analyze the incidence of eclampsia, types of eclampsia, sociodemographic characteristics of the subjects, mode of delivery, maternal and perinatal outcomes over the study period. The study also evaluated the utility of different management protocols followed in the hospital to treat pregnancy with eclampsia.

\section{Materials and Methods}

A retrospective analysis of case records of eclamptic mothers was reviewed from January, 1999 to December, 2008 in the Department of Obstetrics and Gynaecology, Burdwan Medical
College, Burdwan. Burdwan is a district town located approximately $100 \mathrm{Km}$ from Kolkata, capital of West Bengal, India. This is a tertiary care teaching hospital with 1105 beds with more than 17500 deliveries conducted every year. There was $1,40,701$ deliveries during the study period and 5991 eclamptic mothers were studied. All mothers with eclampsia, irrespective of booking status were admitted in the hospital without refuse and they were kept in a separate room. The pregnant women with known seizure disorders were excluded from our study. All of these cases were analyzed with reference to age, gravidity, and socio-economic status, type of eclampsia, mode of delivery, maternal mortality and fate of fetus. In the study period of the year1999-2000, out of 1280 eclamptic mothers the lytic cocktail (menon's regime) was used in $640(50 \%)$ cases and diazepam regime was used in $640(50 \%)$ cases respectively. During the year of 2001-2002, phenytoin sodium was solely used as an anticonvulsant for the treatment of 1315 eclamptic mothers. In the year 2003-2004, out of 1044 cases, injection magnesium sulphate was used in 940 cases (90\%) and Inj. phenytoin sodium was used in $104(10 \%)$ cases. Two thousand and three hundred fifty two mothers with eclampsia were treated exclusively with inj. magnesium sulphate 
$\left(\mathrm{MgSO}_{4}\right)$ regime in the year 2005-2008. After stabilization of patients with different anticonvulsant drugs at different phases of the study period, obstetric management was undertaken and detailed analysis was recorded in a predesigned proforma.

The statistical analysis was done in Microsoft excel by ANOVA- two ways without replication and chi square test. p-value $<0.05$ is considered significant.

\section{Results}

Table I depicts the maternal characteristics. Eclampsia was more common below 20 years $(6.97 \%)$ of age group, primimother $(7.43 \%)$, lower socio-economic status $(5.67 \%)$ and in unbooked $(6.41 \%)$ cases.

Recurrence of convulsion was lowest (5.7\%) in inj. magnesium sulphate groups when compared with phenytoin sodium (10.9\%), menon (32.8\%) and diazepam $(40.3 \%)$ regimes used for treatment of convulsion in eclamptic mothers (Table II). The mean induction delivery interval was highest (22.23 hrs) in diazepam group and lowest (12.75 hrs) in phenytoin sodium groups but is not statistically significant ( $p$ value $=0.305$ ) (Table III).

Table IV shows the different mode of delivery. The lower segment caesarean section (LSCS) rate was higher in $\mathrm{MgSO}_{4}(27.55 \%)$ and phenytoin sodium group $(22.63 \%)$ when compared to menon and diazepam groups.

Table I: Socio-demographic profile of eclamptic mothers

\begin{tabular}{lccc}
\hline Age (Yrs) & No. of deliveries & Ecalmpsia(no.) & Eclampsia (\%) \\
$<20$ & 49625 & 3463 & $6.97 \%$ \\
$20-25$ & 37031 & 880 & $2.37 \%$ \\
$25-30$ & 32421 & 847 & $2.61 \%$ \\
$30-35$ & 20678 & 771 & $3.72 \%$ \\
$>35$ & 946 & 30 & $3.17 \%$ \\
Total & & & \\
Gravidity & No. of deliveries & Eclamptics & Eclampsia and \\
& & & gravidity \\
1 & 69435 & 5165 & $7.43 \%$ \\
2 & 48344 & 527 & $1.09 \%$ \\
3 & 19704 & 180 & $0.91 \%$ \\
4 or more & 3218 & 119 & $3.69 \%$ \\
S-E status & No. of deliveries & Eclamptics & Eclampsia \& S-E \\
& & & status \\
High & 5534 & 230 & $0.90 \%$ \\
Middle & 35372 & 1232 & $3.48 \%$ \\
Low & 79795 & 4529 & $5.67 \%$ \\
Residence & No.of deliveries & Eclamptics & Eclampsia \& \\
& & & residence \\
Urban & 48371 & 995 & $2.05 \%$ \\
Rural & 92330 & 4996 & $5.41 \%$ \\
Religion & No. of deliveries & Eclamptics & Eclampsia \& \\
Hindu & 74729 & 3783 & religion \\
Muslim & 65972 & 2208 & $5.06 \%$ \\
Antenatal Care No.of deliveries & Eclamptics & Eclampsia \& ANC \\
Booked & 68310 & 1349 & $1.97 \%$ \\
Unbooked & 72391 & 4642 & $6.41 \%$ \\
\hline S-E Soio & & &
\end{tabular}

S-E: Socioeconomic; ANC: Antenatal Care
The overall perinatal mortality was $30.33 \%$ in the study period. In the year 1999-2000 (regimes used menon and diazepam) the perinatal mortality was $54.1 \%, 32.5 \%$ in the year $2001-2002$ (regimes used only ph. Sodium) and lowest (22.4\%) in the year 2005-2008, when only injection $\mathrm{MgSO}_{4}$ was used (Table V). The incidence of low birth weight babies was $15.68 \%$ in the last 3 years but the overall incidence of $\mathrm{lbw}$ in the study period was $26.96 \%$ (1254/4651) (Table VI). The contribution of maternal mortality due to eclampsia in the year 2007 and 2008 were $30.98 \%$ and $24.63 \%$ respectively. There were 363 maternal deaths out of 5991 eclamptic mothers giving on overall case fatality rate of $6.05 \%$ (Table VII). Cases of epistaxis were investigated among 1135 mother with eclampsia in 2007-2008 and all the 23mothers were found to have traumatic epistaxis.

Table II: Number of patients having recurrence of convulsion

\begin{tabular}{llllll}
\hline $\begin{array}{l}\text { Parameters Menon } \\
(n=640)\end{array}$ & $\begin{array}{l}\text { Diazepam } \\
(n=640)\end{array}$ & $\begin{array}{l}\text { Ph. Sodium } \\
(n=1419)\end{array}$ & $\mathrm{MgSO}_{4}$ & Statistics*3292) \\
\hline Recurrence & $210(32.8)$ & $258(40.3)$ & $156(10.9)$ & $187(5.7)$ & $\mathrm{F}=13.72034$ \\
of fits & & & & & F crit=5.1432253 \\
APE & 179 & 135 & 99 & 109 & $p$-value $=0.00576$ \\
IPE & 08 & 16 & 12 & 25 & \\
PPE & 23 & 107 & 45 & 53 & \\
\hline
\end{tabular}

*ANOVA-Two factors without replication, the rows (different types of eclampsia) have a significant effect as F-value is larger than the critical value n (\%); APE, Ante partum eclampsia, IPE, Intrapartum Eclampsia, PPE, Postpartum eclampsia.

Table III: Mean Induction Delivery (I-D) Interval

\begin{tabular}{llll}
\hline Regimes & $\begin{array}{l}\text { Time (hour) } \\
\text { Mean (SD) }\end{array}$ & Statistics & p-value \\
\hline Menon & $20.02(3.5)$ & F-2863.25 & p $<0.0001$ \\
Diazepam & $22.23(3.2)$ & & \\
Ph. Sodium & $12.75(2.4)$ & & \\
$\mathrm{MgSO}_{4}$ & $14.12(1.7)$ & & \\
\hline
\end{tabular}

SD, Standard deviation; one way ANOVA

Table IV: Mode of Delivery

\begin{tabular}{|c|c|c|c|c|}
\hline $\begin{array}{l}\text { No. of cases } \\
(\mathrm{n}=4598)\end{array}$ & $\begin{array}{l}\text { Menon } \\
(\mathrm{n}=515)\end{array}$ & $\begin{array}{l}\text { Diazepam } \\
(\mathrm{n}=515)\end{array}$ & $\begin{array}{l}\mathrm{Ph} \text {. Sodium } \\
(\mathrm{n}=1052)\end{array}$ & $\begin{array}{l}\mathrm{MgSO}_{4} \\
(\mathrm{n}=2516)\end{array}$ \\
\hline VD (2682) & $360(69.90)$ & $387(75.15)$ & $671(63.78)$ & $1264(50.23)$ \\
\hline Forceps (882) & $111(21.56)$ & $73(14.17)$ & $139(13.21)$ & $559(22.22)$ \\
\hline Craniotomy(11) & $04(0.77)$ & $03(0.59)$ & $04(0.38)$ & - \\
\hline LSCS (1023) & 40(7.77) & $52(10.09)$ & $238(22.63)$ & 693(27.55) \\
\hline
\end{tabular}

VD: vaginal delivery; LSCS: Lower segment caesarean section, Death of undelivered mother-37; All PPE cases(1356) excluded; $\mathrm{n}(\%)$, ANOVA-two factors without replication: The rows (different methods of delivery have a significant effect as F-value (9.55140) is larger than the critical value (3.86254) and $\mathrm{p}$ value $=0.003701$. 
Table V: Fate of Fetus

\begin{tabular}{|c|c|c|c|c|c|c|c|}
\hline Yea & $\begin{array}{c}\text { Delivery } \\
\text { of } E C L \text { mother } \\
n=5991\end{array}$ & $\begin{array}{c}\text { PPE } \\
n=135\end{array}$ & $\begin{array}{l}M D \\
n=37\end{array}$ & $\begin{array}{c}\mathrm{MP} \\
\mathrm{n}=53\end{array}$ & $\begin{array}{l}\text { Babies } \\
n=4651\end{array}$ & $\begin{array}{c}\text { SB } \\
n=1054 \\
(22.66 \%)\end{array}$ & $\begin{array}{l}\text { NND } \\
n=357 \\
(7.67 \%)\end{array}$ \\
\hline $1999-2000$ & 01280 & 540 & 11 & $8^{a}(16)$ & 745 & $273(36.7)$ & $130(17.4)$ \\
\hline $2001-2002$ & 21315 & 390 & 09 & ga (18) & 934 & $209(22.4)$ & $94(10.1)$ \\
\hline $2003-2004$ & $4 \quad 1044$ & 210 & 05 & $3^{a}(06)$ & 835 & $180(21.6)$ & $45(5.4)$ \\
\hline $2005-2008$ & 82352 & 216 & 12 & $\begin{array}{l}5^{\mathrm{a}}(10) \\
1^{\mathrm{b}}(03)\end{array}$ & 2137 & $392(18.3)$ & $88(4.1)$ \\
\hline
\end{tabular}

ECL: eclamptic; Total no. of babies (4651)=Total no.of ecl mothers (5991)-1356 [post partum eclampsia (PPE)]-37 [undelivered maternal death (MD)]+53 [no. of multiple pregnancies (MP), $n$ ${ }^{\mathrm{a}}$ Twin pregnancies; ${ }^{\mathrm{b}}$ Triplet (no. of babies)]; SB-still birth, $\mathrm{n}(\%)$; NND-neonatal death, $\mathrm{n}(\%)$

[Perinatal mortality $(\mathrm{PNM})=\mathrm{SB}+\mathrm{NND}=1054(22.66 \%)+357(7.67 \%)$ $=1411(30.33 \%)]$

ANOVA: Two factors without replication- The column (fate of the fetus have a significant effect because the F-value (15.9367) is larger than F crit (10.12796); p-value 0.028154

INCIDENCE OF ECLAMPSIA

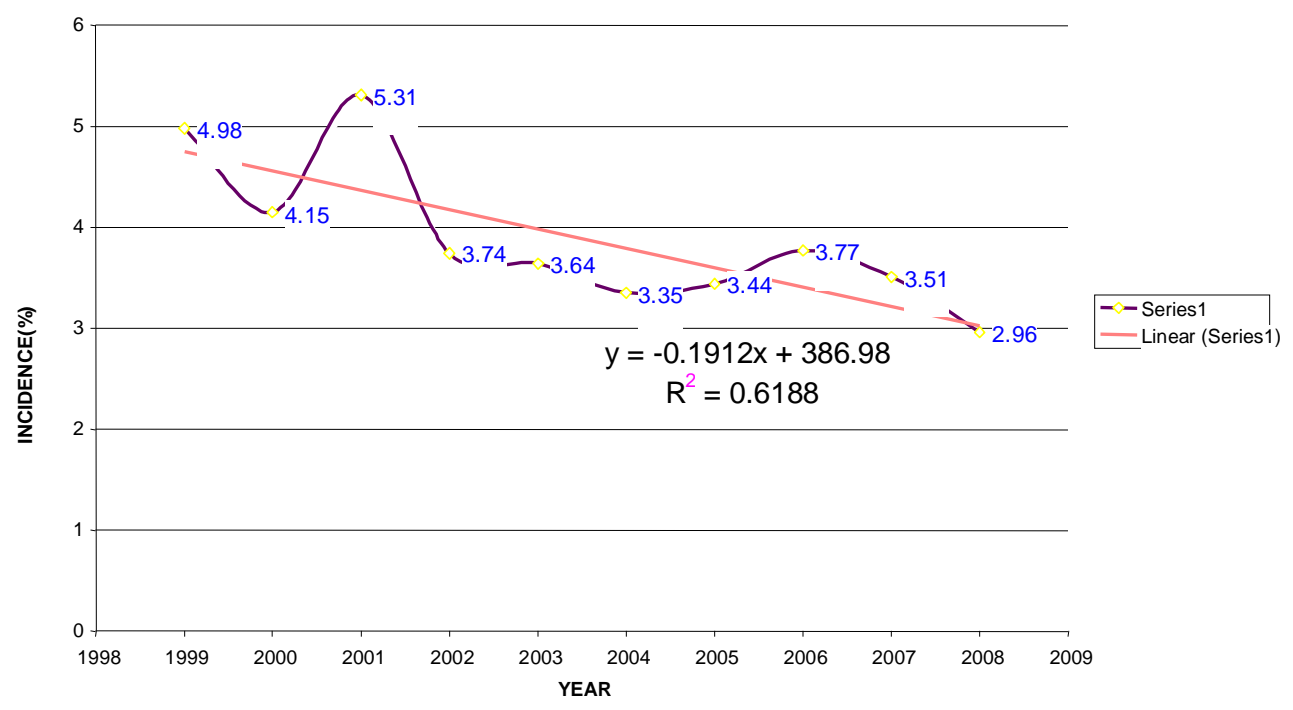

Fig.1- Incidence of eclampsia

$\mathrm{R}^{2}$ value shows that about $61 \%$ of the variation in incidence is explained by time factor (years) through the linear model

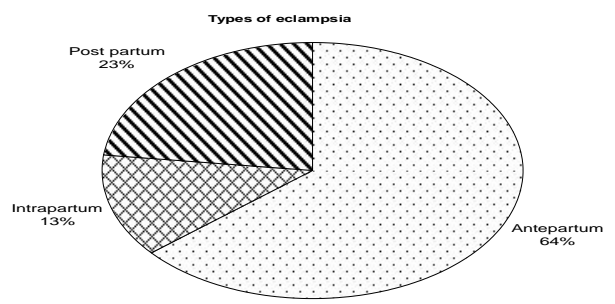

Fig.2- Types of eclampsia

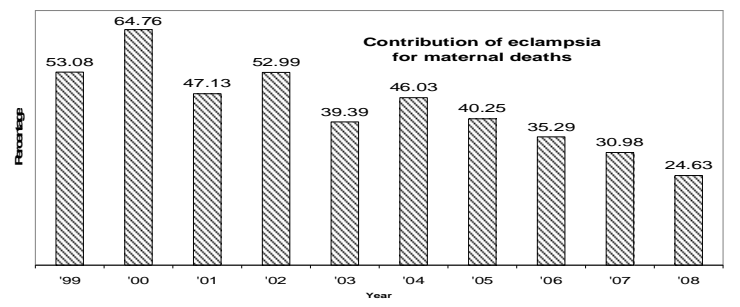

Fig. 3: Contribution of eclampsia for maternal deaths
Table VI: Low Birth Weight babies in eclampsia

\begin{tabular}{llllc}
\hline Year & $\begin{array}{l}\text { No. of babies } \\
(\mathrm{n}=4651)\end{array}$ & BW $(\mathrm{g})$ & \multicolumn{2}{c}{ LBW $[\mathrm{n}=1254(26.96 \%)]$} \\
& Column (\%) & Mean (range) & Yes n(row \%) & No n(row \%) \\
\hline Total & 4651 & $3060(2221)$ & & \\
$1999-2000$ & $745(16.01)$ & $3060(2111)$ & $453(60.8)$ & $292(39.19)$ \\
$2001-2002$ & $934(20.09)$ & $3020(1632)$ & $347(37.1)$ & $587(62.9)$ \\
$2003-2004$ & $835(17.95)$ & $2961(1510)$ & $119(14.25)$ & $716(85.75)$ \\
$2005-2008$ & $2137(45.95)$ & $3040(1701)$ & $335(15.68)$ & $1802(84.32)$ \\
\hline
\end{tabular}

BW: Birth weight; LBW: Low birth weight

Table VII: Case fatality rate and contribution of eclamptic maternal death

\begin{tabular}{lcllll}
\hline Year & $\begin{array}{c}\text { No. of } \\
\text { eclampsia } \\
(\mathrm{m})\end{array}$ & $\begin{array}{c}\text { Maternal } \\
\text { death } \\
(\mathrm{n})\end{array}$ & $\begin{array}{c}\text { Death due } \\
\text { to eclampsia } \\
(\mathrm{p})\end{array}$ & $\begin{array}{c}\text { Case fatality } \\
\text { rate( }(\mathrm{F}) \\
\mathrm{F}=\mathrm{p} / \mathrm{m} \%\end{array}$ & $\begin{array}{l}\text { Contribution } \\
\text { to death }(\mathrm{C}) \\
\mathrm{C}=\mathrm{p} / \mathrm{n} \%\end{array}$ \\
\hline 1999 & 678 & 81 & 43 & 6.34 & 53.08 \\
2000 & 602 & 105 & 68 & 11.29 & 64.76 \\
2001 & 789 & 87 & 41 & 5.20 & 47.13 \\
2002 & 526 & 117 & 62 & 11.79 & 52.99 \\
2003 & 531 & 66 & 26 & 4.89 & 39.39 \\
2004 & 513 & 63 & 29 & 5.65 & 46.03 \\
2005 & 574 & 77 & 31 & 5.40 & 40.25 \\
2006 & 643 & 68 & 24 & 3.73 & 35.29 \\
2007 & 624 & 71 & 22 & 3.52 & 30.98 \\
2008 & 511 & 69 & 17 & 3.32 & 24.63 \\
\hline Total & 5991 & 804 & 363 & 6.05 & 45.14 \\
\hline
\end{tabular}


$1.97 \%$ of booked cases in our study. The incidence of eclamptic convulsions was higher $(6.41 \%)$ in unbooked cases as they were unidentified for prompt treatment of pregnancy induced hypertension (PIH), which increases the incidence of eclampsia. The majority of cases $(64 \%)$ were antepartum eclampsia in our series. Antepartum eclampsia is also very common in different studies and the incidence were $29.13 \%^{3}, 51.2 \%^{5}$ and $60.2 \%$, but a few studies reported the predominance of intrapartum eclampsia over the antepartum eclampsia ${ }^{10}$, and postpartum eclampsia has an upward trend ${ }^{7}$. Previously there was no standard protocol for obstetric management in eclampsia and vaginal delivery was more preferable with more relaxation of inductiondelivery (I-D) interval for fear of caesarean section complications, but now caesarean delivery is the method of choice if vaginal delivery is not anticipated within 12 hours from the onset of convulsion and even after induction. Early caesarean section was also performed in repeated recurrence of convulsion. Anticonvulsant likeinj $\mathrm{MgSO}_{4}$ used for stabilization of eclamptic mother had less recurrence of convulsion $(5.71 \%)$ [Table II]. Normal vaginal delivery occurred in $58.32 \%$ (2682/4598) of cases. Second stage of labour was made cut short by forceps in 882 cases. Caesarean section was performed in $22.25 \%$ (1023/4598) of cases in our series. Agarwal et $\mathrm{al}^{9}$ reported similar incidence $(22 \%)$ of caesarean section. Many centres liberalised caesarean section for better maternal and fetal outcome. The reported incidence varies between $49-70 \% \%^{7,8,12}$.

The perinatal outcome in our study was low birth weight $(26.96 \%, 1254 / 4651)$, still birth $(22.7 \%$; $1054 / 4651)$ and neonatal death $(7.67 \% ; 357 / 4651)$. Our observation was similar with the findings of Agarwal et $\mathrm{al}^{9}$. Reports from different hospitals showed a high still birth rate ${ }^{5,9,10,12}$. The perinatal mortality was $31 \%$ in ph.sodium, $41 \%$ in $\mathrm{MgSO}_{4}$ and $58.1 \%$ in menon's regime ${ }^{13}$. Prematurity, low birth weight, placental insufficiency, late arrival were the contributing factors of perinatal loss in our study. Magnesium sulphate regime can reduce the perinatal mortality to a reasonable standard of $22.4 \%$ (Table V) in our report and it was comparable with the findings of Desai et $\mathrm{al}^{6}$.

The maternal mortality was $10.72 \%$ which comprised $14.08 \%$ of all maternal deaths ${ }^{5}$. Maternal mortality was $6.05 \%$ in our series. It is a low figure than other Indian studies ${ }^{2-4,10}$. Haphazard combinations of sedative and anticonvulsants and improper management of labour in different centres are important factors for high maternal mortality in eclampsia. In the present series death of eclamptic mothers formed the main bulk $(45.14 \%)$ of maternal death (Table VII). Regarding the choice of anticonvulsant, it was noted that the introduction of inj. magnesium sulphate dropped the maternal death in eclampsia in the last four years [mean 23.5 (range 17-31)] (Table VII). The contribution of eclamptic maternal death is also reduced in the last two years (27.85\%) [Fig-3] but still is higher on comparison to world standard. This is mainly due to late referral, poor antenatal check up, and transfer of moribund patient just before death to the tertiary hospital

Conclusion: Eclampsia still remains the major problem in developing countries. Incidence of perinatal mortality and maternal mortality is disappointing in eclampsia. Poor socio-economic status, lack of essential obstetric care is the fundamental determinants of maternal deaths not only for eclampsia but as a whole. Unless the social, educational status are uplifted and antenatal coverage is brought to the grass root level no miracle can be expected. A moderate reduction of death of both mother and fetus in our institution is possible due to wider use of magnesium sulphate; timed delivery and proper implementation of emergency obstetrics care (EmOC) facilities to mothers with eclampsia.

\section{Acknowledgement}

We are indebted to the Medical Superintendent Cum Vice-Principal of Burdwan Medical College, Burdwan for allowing us to use the hospital records for our study.

\section{References}

1. WHO-Causes of maternal deaths: Global estimation in reduction of maternal mortality: A joint WHO/ UNFPA/UNICEF/World bank statement. Geneva: WHO, 1999.

2. Coyaji BJ. Maternal mortality and morbidity in the developing countries like India. J Matern Child Health Ind 1991; 2: 3-9.

3. Saha S, Ghosh Roy S, Ganguli RP et al. Comparative study of efficacy of magnesium sulphate and diazepam in the management of eclampsia in a peripheral rural medical college (A cross over study of 440 cases). J Obstet Gynecol Ind 2002; 52:69-72.

4. Nobis PN. Maternal outcome in eclampsia. J Obstet Gynecol Asia 2002; 6:25-28.

5. Pal B, Niyogi G, Patkar V. Maternal mortality in eclampsia. J Obstet Gynecol Ind 1997; 47:11-7.

6. Desai P, Badhenka H, Barbhaya M, Desai M, et al Changes in perinatal outcome due to magnesium sulphate in eclampsia. J Obstet Gynecol Ind 1995; 45:732-35.

7. Kamilya G, Bhattacharrya SK, Mukherjee J. Changing trends in the management of eclampsia from a teaching hospital, JIMA 2005; 103:132-5. 
8. Eclampsia Trial Collaborative Group - Which anticonvulsant for women with eclampsia? Evidence from the collaborative eclampsia trial, Lancet 1995; 345:1455-63.

9. Agarwal K, Goswami D, Tempe A. Maternal and perinatal outcome in women with antepartum eclampsia at a tertiary care hospital. J Obstet Gynecol Ind 2004; 7:27-30.

10. Majhi AK, Chakraborty PS, Mukopadhyay A. Eclampsia - Present scenario in a referral medical college hospital. J Obstet Gynecol Ind 2001; 51:143-7.
11. Samal S, Gupta U et al. Use of nifedipine and low magnesium sulphate in PIH. J Obstet Gynecol Ind 1999; 49:38-40.

12. Begum MR, Begum A, Quadir E. Loading dose versus standard regime of magnesium sulphate in the management of eclampsia: a randomized trial. J Obstet Gynecol Research 2002; 28:154-59.

13. Hangara US, Pragya S. A comparative study of phenytoin sodium with magnesium sulphate and menon's regime in the treatment of eclampsia. J. Obstet Gynecol Ind 1997; 47:11-7. 